\title{
COVID-19 Outbreak in Italy: Report on the First 124 Consecutive Patients Treated at Home
}

\author{
Luigi Cavanna, ${ }^{1}$ Gabriele Cremona, ${ }^{1}$ Chiara Citterio, ${ }^{1}$ Camilla Di Nunzio, ${ }^{1}$ \\ Monica Muroni, ${ }^{1}$ Anna Maria Andena, ${ }^{2}$ Evelina Cattadori, ${ }^{3}$ Mirella Gubbelini, ${ }^{4}$ \\ Lara Muroni, ${ }^{4}$ Roberta Schiavo, ${ }^{5}$ Massimo Nolli, ${ }^{6}$ Mauro Codeluppi, ${ }^{7}$ \\ Pietro Maniscalco ${ }^{8}$ and Guido Pedrazzini ${ }^{9}$
}

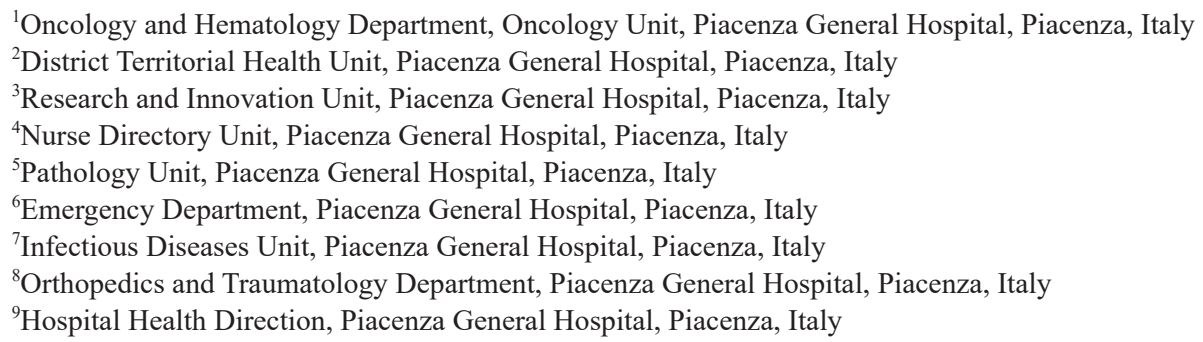

North Italy emerged as an epicenter of COVID-19 in the Western world. The majority of studies of patients with COVID-19 have focused on hospitalized patients, and data on early outpatient treatment are limited. This research retrospectively examines consecutive symptomatic adults who did not present to a hospital but who experience laboratory confirmed (nasopharyngeal swabs) or probable COVID-19 infection. From March 12 to April 12, 2020, 124 consecutive patients with laboratory-confirmed COVID-19 infection (84\%) or with epidemiologically linked exposure to a person with confirmed infection (16\%) were managed at home. The diagnosis of pneumonia was made with a portable ultrasound. COVID-19 treatment was based on low-dose hydroxychloroquine with or without darunavir/cobicistat or azithromycin and enoxaparine for bedridden patients. The patients were monitored by telemedicine. The primary endpoints were clinical improvement or hospitalization, and the secondary endpoints were mortality at day 30 and at day 60 . Forty-seven (37.9\%) patients had mild COVID-19 infection, $44(35.5 \%)$ had moderate COVID-19 infection, and $33(26.6 \%)$ had severe COVID-19 infection. Four patients $(3.2 \%)$ were hospitalized and there were no deaths at day 30 and at day 60 . Only mild side effects were reported. Early home treatment of COVID-19 patients resulted in a low hospitalization rate with no deaths, with the limitations of the small sample size and that it was conducted within a single geographic area. We believe that this model may be easily reproduced in both cities and rural areas around the world to treat COVID-19 infection.

Keywords: COVID-19; home care; outpatient; treatment

Tohoku J. Exp. Med., 2021 September, 255 (1), 61-69

\section{Introduction}

In December 2019, a new pathogen-enveloped RNA beta coronavirus was identified and named severe acute respiratory syndrome coronavirus 2 (SARS-CoV-2) which causes severe pulmonary disease in $14 \%$ of infected people (Izcovich et al. 2020; World Health Organization 2020). The World Health Organization declared coronavirus dis- ease 2019 (COVID-19), caused by SARS-CoV-2, a public health emergency of international concern, and declared a pandemic (Worldometer 2020). The first COVID-19 infection in Italy was reported in the Lombardy region on February 21, 2020. This first case was followed by an immediate rapid rise in additional cases. In Italy, the most highly infected regions were Lombardy, Emilia Romagna, and Veneto. The city of Piacenza (Emilia Romagna

Received June 12, 2021; revised and accepted June 30, 2021. Published online September 28, 2021; doi: 10.1620/tjem.255.61

Correspondence: Luigi Cavanna, Oncology and Hematology Department, Oncology Unit, Piacenza General Hospital, Via Taverna 49, Piacenza 29121, Italy.

e-mail: 1.cavanna@ausl.pc.it

(C)2021 Tohoku University Medical Press. This is an open-access article distributed under the terms of the Creative Commons Attribution-NonCommercial-NoDerivatives 4.0 International License (CC-BY-NC-ND 4.0). Anyone may download, reuse, copy, reprint, or distribute the article without modifications or adaptations for non-profit purposes if they cite the original authors and source properly.

https://creativecommons.org/licenses/by-nc-nd/4.0/ 
Region) is very near (10 minutes by car) to the epicenter of the outbreak of COVID-19, and the catastrophic nature of Lombardy's outbreak has been widely publicized (Horowitz 2020).

Clinical and pathological features of patients with COVID-19 have been reported, showing that SARS-CoV-2 infection causes clusters of severe and even fatal symptoms (Wynants et al. 2020). The National Health Commission published guidelines that classified SARS-CoV-2 infections into four groups: mild type, moderate type, severe type, and critical type (Feng et al. 2020; Lai et al. 2020).

Hydroxychloroquine (HCQ), with or without antiviral treatment, has been incorporated into our national guidelines to treat COVID-19 (Cavanna et al. 2020; SIMIT 2020; Stroppa et al. 2020), and was available until May 26, 2020. In the district of Piacenza, a week after the first COVID-19 infection was reported in Italy, the emergency department of the Piacenza Hospital was overcrowded with people infected with COVID-19 who were already in serious condition. All these patients had a story of days or weeks spent at home with fever, cough, fatigue, exertional dyspnea at first, and then dyspnea at rest, which finally required urgent hospitalization. All these patients were treated at home with antipyretics, such as paracetamol. Several patients were given large spectrum antibiotics, such as amoxicillin, and no patients were treated with HCQ or antiretroviral or azithromycin (AZ). Patients who were admitted to the Piacenza Hospital were treated with HCQ tablets (400 mg daily) plus darunavir and cobicistat (DC) $(800 / 150 \mathrm{mg}$ daily) for seven days (Stroppa et al. 2020). To avoid this rapid progression of COVID-19 symptoms in future patients, we decided to provide early at-home treatment to COVID-19 infected patients at the onset of their symptoms. In this study, we performed a comprehensive retrospective evaluation of patients with COVID-19 infection (mild, moderate, and severe type) precociously treated at home in the district of Piacenza from March 12 to April 12, 2020.

\section{Materials and Methods}

In the district of Piacenza (North Italy), a task force was established to diagnose, treat, and monitor patients infected with COVID-19. The task force was comprised of units, each involving a medical doctor and a nurse equipped with personal protective equipment, a car, a portable ultrasound, portable electrocardiography finger oximeters, kits for nasopharyngeal swabs and blood samples, and drug kits that contained DC (800/150 mg), HCQ tablets $(200 \mathrm{mg})$, steroids, prednisone $(25 \mathrm{mg})$, subcutaneous enoxaparin $(4,000$ or 6,000 Unit), and AZ tablets $(500 \mathrm{mg})$. Blood samples were taken at home and brought back to the Piacenza Hospital and included a complete blood count, a basic metabolic panel, and a coagulation panel. The levels of white blood cell and C-reactive protein did not affect the decision of administering antiviral drugs. Patients with suspected symptoms of COVID-19 infection such as fever, cough, and dyspnea could call the task force or their family doctor, that activates the task force, that would promptly visit their home. This program was called "The Piacenza Model" (Fig. 1). COVID-19 severity was classified as follows in accordance with guidelines for diagnosis and treatment (Feng et al. 2020): (1) mild type, in which the clinical symptoms are mild with no abnormal radiological findings; (2) moderate type, in which fever, cough, and other symptoms are presented with pneumonia on chest computed tomography or sonography; (3) severe type, in which one of the following conditions is met: respiratory distress, respiratory rate $\geq 30$ per min, oxygen saturation in room air at rest $\leq 93 \%$, or partial pressure of oxygen in arterial blood / fraction of inspired oxygen $\leq 300 \mathrm{mmHg}$; and (4) critical type, in which the patient experiences respiratory failure occurs and mechanical ventilation is required, or shock occurs. Patients with organ dysfunction must be monitored and treated in an intensive care unit. Chest ultrasound was performed at home as previously reported by an expert physician (Nouvenne et al. 2020; Yang et al. 2020a) (Fig. 2) and nasopharyngeal swab specimens were collected according to the Center for Disease Central and Prevention Guidelines and performed with reverse transcription polymerase chain reaction (RT-PCR) (Centers for Disease Control and Prevention 2020). For patients without a recent electrocardiogram (ECG) and with a history of heart disease, an ECG was carried out to allow HCQ therapy. The diagnosis of COVID-19 was based on typical symptoms and lung involvement on chest ultrasonography, and it was confirmed by RT-PCR for SARS-CoV-2 detection in the majority of patients. However, in patients without RT-PCR for SARS-CoV-2 detection, the diagnosis of COVID-19 was based on compatible symptoms after a high risk exposure.

Patients with mild type COVID-19 infection and without risk factors were treated only with symptomatic drugs, such as paracetamol (Fig. 3). Treatment with HCQ alone was reserved for patients with mild type who also presented with at least one of the following risk factors: age $\geq 60$ years, obesity, hypertension, diabetes, cancer, chronic obstructive pulmonary disease, and chronic ischemic heart disease (Zheng et al. 2020). For patients with COVID-19 pneumonia causing respiratory illness, the treatment began with HCQ (400 mg) twice daily, followed by $200 \mathrm{mg}$ twice daily alone for six days, or HCQ plus DC $(800 / 150 \mathrm{mg})$ daily for the next seven days. For patients with contraindications to DC, AZ (500 mg) daily for six days was added to HCQ. Some patients received HCQ, AZ, and DC. A finger oximeter was also delivered to each patient. Three times each day, the value of oxygen saturation and clinical symptoms were communicated by the patient using voice or tablet video calls to the task force's nurse. When oxygen saturation ( $\mathrm{SpO} 2)$ was $93 \%$ or less, oxygen therapy was delivered at home. For bedridden patients, subcutaneous enoxaparine (4,000 to 6,000 UI daily) was administered, and when their body temperature was above $38^{\circ} \mathrm{C}$, paracetamol $(500 \mathrm{mg})$ was recommended. Prednisone (35.5 
mg daily) was prescribed to patients with severe dyspnea, 7 days after symptoms onset. Treatment was offered to male and female patients (pregnant patients excluded) 18 years or older. Treatment with HCQ was not used with patients who had prolonged corrected QT interval or a history of favism. Informed consent was obtained from all patients.

\section{Patient monitoring}

A doctor or trained nurses monitored patients using a phone or tablet. Three times each day, they evaluated finger oximetry, fever, cough, dyspnea, fatigue, other symptoms, and the ability to eat or take drugs. Adverse effects of drugs were monitored. Patients with moderate or severe COVID19 type were visited every three days until they recovered. The time of symptoms duration before diagnosis was calculated at the first visit.

\section{Patient outcome measures}

The primary endpoints of this program were clinical improvement or hospitalization. Secondary endpoints were mortality at day 30 and at day 60 . Discontinuation of treatment was registered; adverse events related to the treatment were classified according to the National Cancer Institute Common Terminology Criteria for Adverse Events, Version 4.0, and reported (U.S. Department of Health and Human Services. National Institutes of Health National Cancer Institute 2009).

\section{Statistical analysis}

Each patient was given a unique recognition code. Medical records were recorded on paper-based medical charts, and the following information for each patient was entered in a Microsoft Excel file (Microsoft Office version 2010): age, sex, symptoms and date of onset, comorbidities,

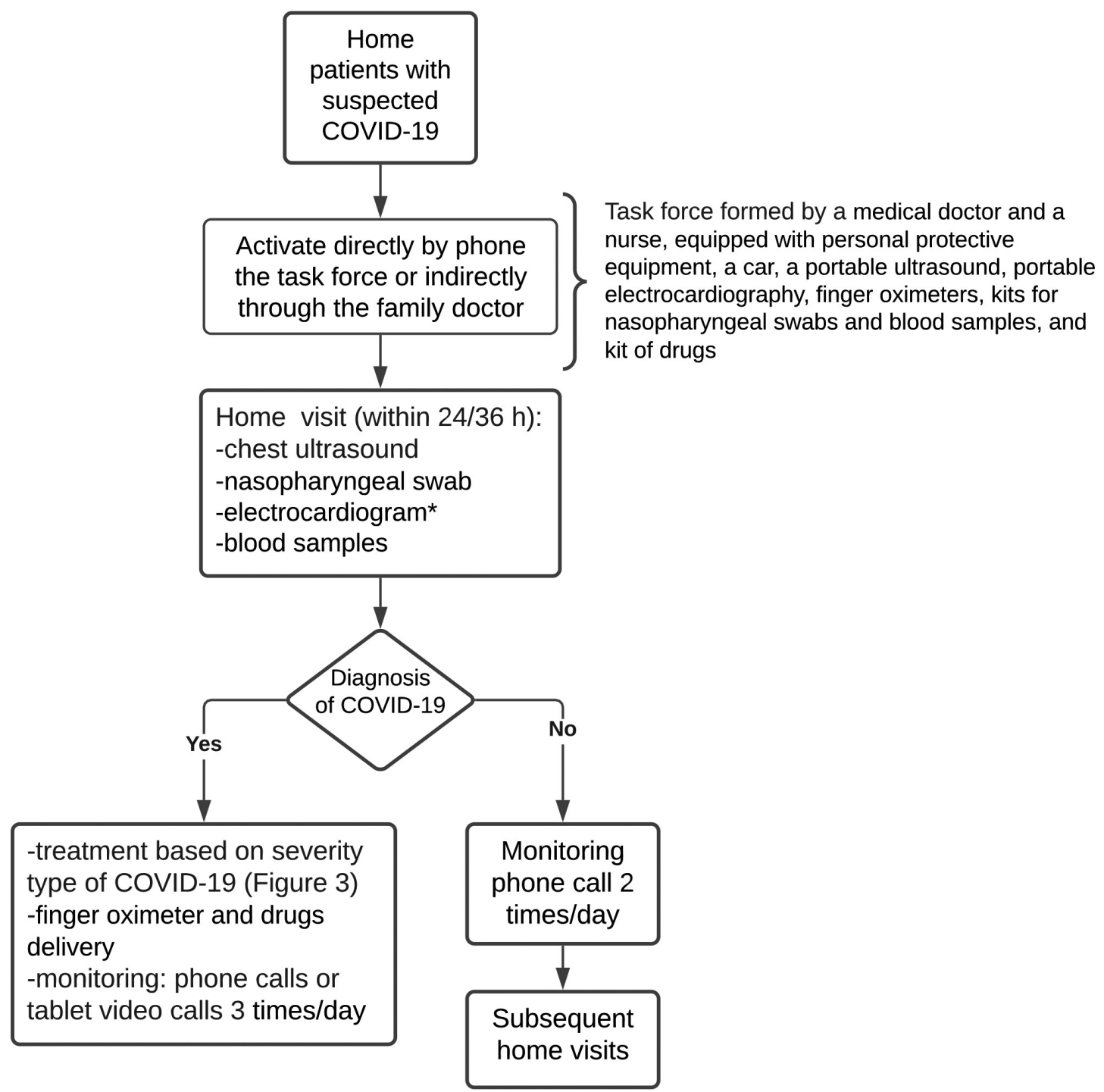

Fig. 1. Overview of the home management of COVID-19 patients ("Piacenza model"). *For patients without a recent electrocardiogram and with a history of heart disease 


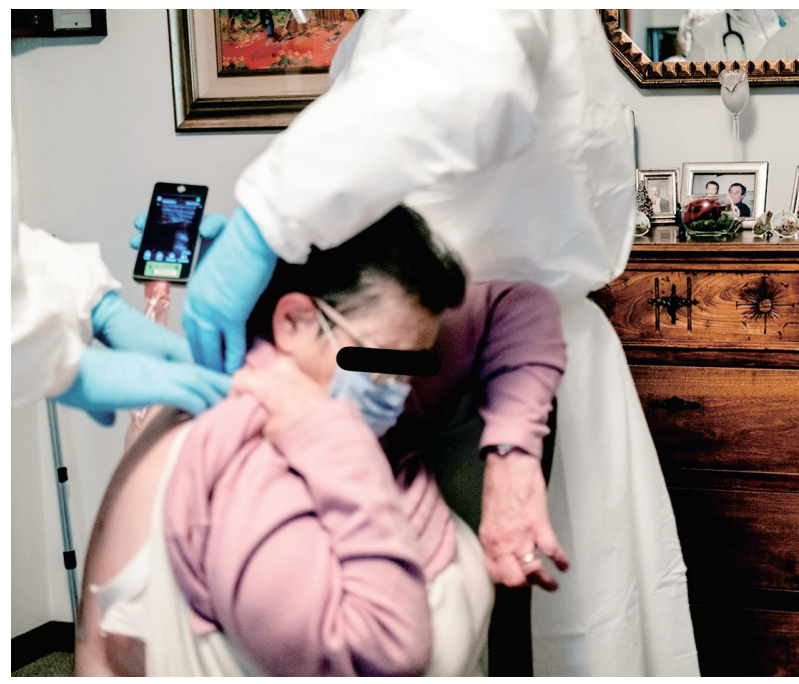

Fig. 2. Picture of the scene of the home visit and lung ultrasound examination.

flu vaccination, COVID-19 therapy, COVID-19 severity, oxygen therapy, hospitalization, and outcome. Quantitative variables are described using mean \pm standard deviation (SD), whereas qualitative variables are described using absolute and percentage frequencies. Comparisons of covariates were conducted using chi square or Fisher's exact test for categorical variables, and one-way ANOVA or the Kruskal-Wallis test was used for continuous variables. All analyses were performed using Stata version 16 statistical software, with two-sided significance tests and p-value $<0.05$.

This retrospective study was approved by the Local
Ethics Committee (Institutional Review Board approval number 418/2020/OSS*AUSLPC).

\section{Results}

All patients visited and treated at home between March 12, 2020 and April 12, 2020 were included in the study. There were 124 COVID-19 patients (Table 1) who had SARS-CoV-2 RT-PCR positive test for COVID-19 infection $(84 \%)$ or who had compatible symptoms after epidemiologically linked exposure to a person with laboratory confirmed infection within the past 14 days (16\%). Given the restrictions in early laboratory testing at the onset of the pandemic, a diagnosis was also accepted as an epidemiological link with household member with a positive nasopharyngeal test result for patients with symptoms coherent and compatible with COVID-19 (Skipper et al. 2020). The patients consisted of 58 men and 66 women, with a mean age of $58.10 \pm 15.63$ years (range 18-91 years). Sixty-eight (54.8\%) patients showed one or more comorbidities: 32 (25.8\%) had hypertension, 10 (8.1\%) had chronic obstructive pulmonary disease, $8(6.5 \%)$ had diabetes, $16(12.9 \%)$ had coronary disease, $13(10.5 \%)$ had cancer, and 26 showed other comorbidities. Forty seven (37.9\%) patients had mild type of COVID-19, 44 (35.5\%) had moderate type and $33(26.6 \%)$ had severe type. Ten $(8.1 \%)$ patients with mild type COVID-19 were younger than 60 years and had no comorbidities, so they did not receive treatment. The remaining 114 patients that showed pneumonia at lung ultrasound examination, were treated with HCQ-based therapy. These patients reported the following symptoms: fever (94.9\%), cough (69.4\%) and dyspnea (25.8\%). The mean duration of symptoms before initiation of treatment was
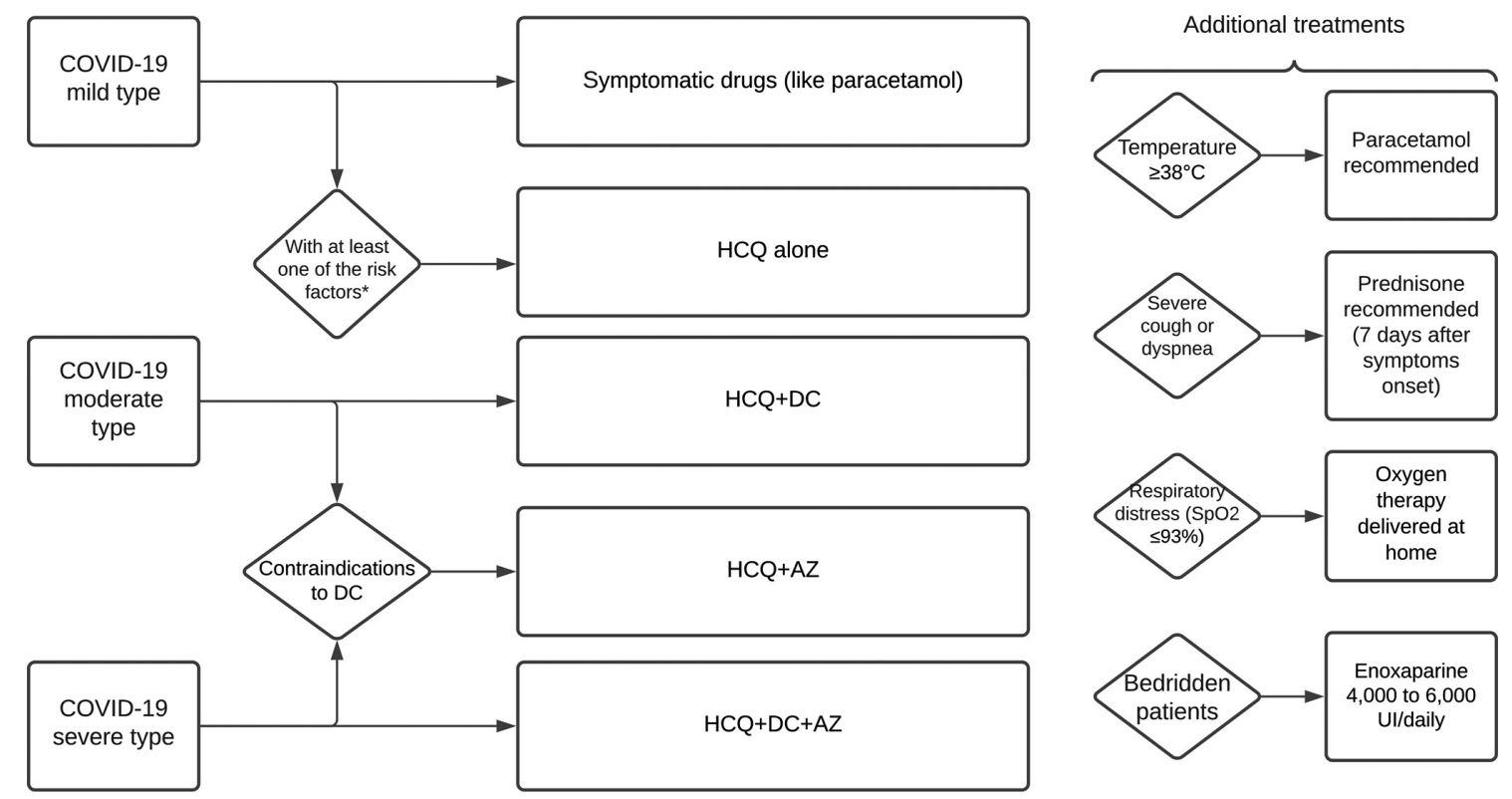

Fig. 3. Flow chart of the therapeutic strategy in each patient's group with different severity type of COVID-19. HCQ, hydroxychloroquine; DC, darunavir/cobicistat; AZ, azithromycin.

*Risk factors: age $\geq 60$ years, obesity, hypertension, diabetes, cancer, chronic obstructive pulmonary disease, and chronic ischemic heart disease. 
Table 1. Clinical, demographic characteristics and outcomes of 124 patients diagnosed with COVID-19 and treated at home.

\begin{tabular}{|c|c|}
\hline Characteristics & $\begin{array}{c}\text { Patients }(\mathrm{n}=124) \\
\mathrm{n}(\%)\end{array}$ \\
\hline \multicolumn{2}{|l|}{ Sex } \\
\hline Male & $58(46.8)$ \\
\hline Female & $66(53.2)$ \\
\hline Comorbidities & $68(54.8)$ \\
\hline Hypertension & $32(25.8)$ \\
\hline Chronic obstructive pulmonary disease & $10(8.1)$ \\
\hline Diabetes & $8(6.5)$ \\
\hline Coronary disease & $16(12.9)$ \\
\hline Cancer & $13(10.5)$ \\
\hline Other & $26(21.0)$ \\
\hline \multicolumn{2}{|l|}{ COVID-19 infection } \\
\hline Mild & $47(37.9)$ \\
\hline Moderate & $44(35.5)$ \\
\hline Severe & $33(26.6)$ \\
\hline \multicolumn{2}{|l|}{ Symptoms } \\
\hline Fever & $114(94.9)$ \\
\hline Cough & $86(69.4)$ \\
\hline Dyspnea & $32(25.8)$ \\
\hline Diarrhea & $17(13.7)$ \\
\hline Fatigue & $19(15.3)$ \\
\hline Dysgeusia & $5(4.0)$ \\
\hline Other & $24(19.4)$ \\
\hline \multicolumn{2}{|l|}{ Outcome } \\
\hline Death at 30 days & $0(0)$ \\
\hline Death at 60 days & $0(0)$ \\
\hline Hospitalized & $4(3.2)$ \\
\hline
\end{tabular}

$7.02 \pm 3.29$ days (range 1-15 days).

The relationship between the severity COVID-19 and patient age showed that patients with severe type of COVID-19 were older than patients with mild or moderate type $(\mathrm{p}=0.003)$ (Table 2$)$. No significant difference was found between the severity of COVID-19 and sex. The relationship between the severity of the disease and the duration of symptoms showed that patients with severe type of COVID-19 had a longer time duration of symptoms when compared with patients with mild or moderate type COVID-19 $(p=0.005)$ (Table 2).

The majority of patients (31.9\%) with mild type COVID-19 were treated with HCQ alone, while the majority of patients with moderate type, with more extensive pneumonia, were treated with HCQ plus AZ (31.8\%). The majority of patients with severe type COVID-19 were treated with HCQ plus DC (27.3\%) and HCQ plus AZ plus DC $(27.3 \%)$. In regards to the primary endpoint, only four patients $(3.2 \%)$ were hospitalized, and all were discharged after a median of four days (range 1-7 days). For the secondary endpoints, no patient died at day 30 or at day 60 (Table 1). For all patients who did not provide a swab test at the onset (14\%), COVID-19 infection was subsequently confirmed by serological antibody detection.

Safety

In general, treatment with HCQ alone, HCQ plus AZ, HCQ plus DC, HCP plus AZ and DC was well tolerated. After initiation of treatment in 114 patients, only 11 (9.7\%) presented adverse events possibly related to the treatment (grades 1-2) (Table 3). Diarrhea was reported in $6.1 \%$ of patients, headache in 3.5\%, nausea/vomiting in $2.6 \%$ and abdominal pain in $2.6 \%$.

Table 2. Relation between the severity of disease and age, onset of symptoms or duration of symptoms.

\begin{tabular}{lcccc}
\hline & \multicolumn{3}{c}{ Severity of COVID-19 } \\
Mild $(\mathrm{n}=47)$ & Moderate $(\mathrm{n}=44)$ & Severe $(\mathrm{n}=33)$ & p-value \\
\hline $\begin{array}{c}\text { Age, mean } \pm \text { SD } \\
\text { (range) }\end{array}$ & $\begin{array}{c}54.72 \pm 18.07 \\
(18-91)\end{array}$ & $\begin{array}{c}55.93 \pm 13.55 \\
(15-89)\end{array}$ & $\begin{array}{c}65.82 \pm 11.74 \\
(41-89)\end{array}$ & $0.003^{\text {a }}$ \\
$\begin{array}{c}\text { Symptoms, } \mathrm{n}(\%) \\
\text { Fever }\end{array}$ & & & \\
Cough & $41(87.2)$ & $40(90.9)$ & $33(100)$ & 0.083 \\
$\begin{array}{l}\text { Dyspnea } \\
\text { Diarrhea }\end{array}$ & $28(59.6)$ & $35(79.6)$ & $23(69.7)$ & 0.118 \\
$\begin{array}{l}\text { Fatigue } \\
\text { Dysgeusia }\end{array}$ & $7(14.9)$ & $6(13.6)$ & $19(57.6)$ & $0.000^{*}$ \\
$\begin{array}{l}\text { Duration of } \\
\text { symptoms (days), } \\
\text { mean } \pm \text { SD } \\
\text { (range) }\end{array}$ & $5(10.6)$ & $6(13.6)$ & $6(18.2)$ & 0.627 \\
\hline
\end{tabular}

${ }^{a}$ p-value: mild vs. moderate, 0.922 ; mild vs. severe, $0.004 *$; moderate vs. severe, $0.014 *$.

${ }^{b}$ p-value: mild vs. moderate, 0.050 ; mild vs. severe $0.000^{*}$; moderate vs. severe $0.000 *$.

$* \mathrm{p}<0.05$ 
Table 3. Adverse events experienced by the patients treated with hydroxychloroquine (HCQ)-based therapy.

\begin{tabular}{lc}
\hline & Treated patients $(\mathrm{n}=114)$ \\
$\mathrm{n}(\%)$
\end{tabular}

\section{Discussion}

The whole spectrum of COVID-19 ranges from mild and self-limiting illness to severe and critical disease with respiratory and multiorgan failure to death (Cao et al. 2020; Cavalcanti et al. 2020). The majority of studies on COVID19 patients concern hospitalized cases (Cao et al. 2020; Cavalcanti et al. 2020; Cunningham et al. 2020; Esposito et al. 2020; Rizk et al. 2020). To date, it has been reported that there are no specific therapeutic agents for coronavirus infections; however, the main therapies being used to treat COVID-19 are HCQ/chloroquine (CQ)-based combination treatment, antiviral drugs, and respiratory/supportive therapy (Cao et al. 2020; Cavalcanti et al. 2020; Cunningham et al. 2020; Esposito et al.2020; Rizk et al. 2020). It must be emphasized that the majority of patients with COVID-19 in China (Wang et al. 2020; Yang et al. 2020b; Zhao et al. 2020) and Western countries (Catteau et al. 2020; Di Castelnuovo et al. 2020; Lombardy Section Italian Society Infectious and Tropical Diseases 2020; Million et al. 2020) were treated after hospital admission in inpatient settings and following several days of symptoms onset (Cunningham et al. 2020; Esposito et al. 2020; Rizk et al. 2020). It has been reported that HCQ alone or with AZ did not improve clinical standard care (Cavalcanti et al. 2020); however, it must be noted that in that study, only hospitalized patients with suspected or confirmed COVID-19 were involved and although the median time from symptom onset to randomization was seven days, patients who had experienced symptoms for up to 14 days after the beginning were included, and it is now known that HCQ treatment is more effective when applied at the onset of the disease.

A French study that involved 1,061 patients treated with HCQ showed that 973 (92\%) demonstrated good clinical outcomes and virological cure with no observed cardiac toxicity (Million et al. 2020). Similar results have been in other studies (Derwand et al. 2020; Di Castelnuovo et al. 2020; Risch 2020). In our study of 124 patients with mild/ moderate/severe type of COVID-19, only four patients $(3.2 \%)$ were admitted to the hospital and discharged after a median of four days (range 1-7 days), and above all, no patients died at day 30 or at day 60 from the start of the treatment. At the beginning of this pandemic disease in our country, the majority of patients were admitted to hospital in worse condition with lung damage and an evolving cytokine storm (Bernardi 2020). HCQ-based therapy for patients with COVID-19 has been used with thousands of patients with COVID-19 around the world (Capucci et al. 2020; Cassone et al. 2020; Catteau et al. 2020; Cipriani et al. 2020; Di Castelnuovo et al. 2020; Million et al. 2020; Ramireddy et al. 2020; Saleh et al. 2020; Skipper et al. 2020). A recent large study has demonstrated that HCQ is not associated with increased short-term risk of cardiovascular toxicity and mortality (Catteau et al. 2020). In addition, recent studies from Italy showed that patients receiving HCQ plus AZ did not show any arrhythmic clinical complications (Cipriani et al. 2020; Di Castelnuovo et al. 2020). Similarly, Saleh et al. (2020) reported that the effects of HCQ and AZ on QT Interval are very limited.

To our knowledge, only four randomized controlled trials of adult outpatients with probable or confirmed COVID-19 treated with HCQ have been published (Davoodi et al. 2020; Johnston et al. 2021; Mitja et al. 2020; Skipper et al. 2020). In the first study a five-day course of HCQ failed to show a substantial clinical benefit in improving the rate of resolution of COVID-19 symptoms in enrolled patients with early, mild COVID-19 (Skipper et al. 2020). However, it must be emphasized that 10 of the $211(4.7 \%)$ eligible participants assigned to the placebo group were hospitalized versus only four of the $212(1.9 \%)$ participants assigned to the HCQ treatment group. In addition, the main limitation of that study is that only $58 \%$ of participants were tested for SARS-CoV-2, which is, in our opinion a limitation. The second study involved a multicenter open-label randomized controlled trial, performed in Spain, and enrolled only patients with mild COVID-19 (Mitja et al. 2020). No benefits were obtained with HCQ treatment in term of reducing the risk of hospitalization or shortening the time to resolve symptoms. However, a limitation of this study was an overrepresentation of healthcare professionals (more than $80 \%$ of the samples) which limits the generalization of these findings. The third study involved 60 adult outpatients with moderate respiratory illness following COVID-19 infection (Davoodi et al. 2020). 
The patients were randomly assigned to receive either Febuxostat (FBX) or HCQ. The authors concluded that the effectiveness of HCQ was not different from FBX in terms of the resolution of clinical manifestations, laboratory test results and lung CT findings. More recently, Johnston et al. 2021, randomly assigned patients to receive HCQ, with or without $\mathrm{AZ}$ or a placebo equivalent. Like the others, this study contains some limitations and biases: the clinical classification of patients included in the study is lacking, and the patients were not assessed for pneumonia by imaging techniques. We also highlight a non-randomized, retrospective study (Derwand et al. 2020), in which a total of 141 COVID-19 patients were treated in an outpatient setting with zinc, low-dose $\mathrm{HCQ}$, and AZ. In that study, no cardiac side effects were observed, and above all, treatment was associated with significantly fewer hospitalizations. Similar results have been reported in other non-randomized studies (Sulaiman et al. 2020; Mohana et al. 2021; Sogut et al. 2021).

The main limitations of this study are the small sample size and that it was conducted within a single geographic area.

In conclusion, we are aware that safety of managing COVID-19 patients at home may be suggested and not evidenced from the present study, due to the small number of observed patients. We believe that the present report may represents a valuable attempt of the home treatment of COVID-19 patients. We believe that our model, previously mentioned by Maniscalco et al. (2020), which is based on a clinical visit, lung ultrasound, nasopharyngeal swab, home treatment [studies on new treatments are ongoing or just published (Feld et al. 2021; Tardif et al. 2021)] and telemedicine monitoring, will reduce hospitalization of COVID-19 patients. SARS-CoV-2 infection will decrease since vaccination is ongoing; however, early home treatment of COVID-19 patients can result in a very low hospitalization rate, as seen with our series of 124 consecutive COVID-19 patients; $62.1 \%$ of them were a moderate/severe type. In our cohort of patients treated precociously at home, no deaths were registered. Ideally, however, large randomized clinical trials are needed in this subset of patients to establish better outpatient treatment for COVID19 infection.

\section{Acknowledgments}

The authors dedicate this work to all the patients died because of COVID-19 in the district of Piacenza and their relatives, and wish to thank the General Director of the Local Health System, Ing. Luca Baldino.

\section{Conflict of Interest}

The authors declare no conflict of interest.

\section{References}

Bernardi, F. (2020) The Italian doctor flattening the curve by treating COVID-19 patients in their homes. http://time.com/5816874/italy-coronavirus-patients-treating-home/ [Accessed: June 03, 2021].

Cao, B., Wang, Y., Wen, D., Liu, W., Wang, J., Fan, G., Ruan, L., Song, B., Cai, Y., Wei, M., Li, X., Xia, J., Chen, N., Xiang, J., Yu, T., et al. (2020) A trial of Lopinavir-Ritonavir in adults hospitalized with severe Covid-19. N. Engl. J. Med., 382, 1787-1799.

Capucci, A., Santarelli, A., Bartolomei, M., Paolizzi, C., Biagetti, C., Dappozzo, A. \& Piovaccari, G. (2020) Low hospitalization rate without severe arrhythmias: a prospective survey on 350 patients early home treated with hydroxychloroquine during COVID-19 pandemic. J. Cardiovasc. Med. (Hagerstown), 21, 922-923.

Cassone, A., Iacoviello, L. \& Cauda, R. (2020) Knowing more about chloroquine/hydroxycloroquine in COVID-19 patients. Future Microbiol., 15, 1523-1526.

Catteau, L., Dauby, N., Montourcy, M., Bottieau, E., Hautekiet, J., Goetghebeur, E., van Ierssel, S., Duysburgh, E., Van Oyen, H., Wyndham-Thomas, C. \& Van Beckhoven, D.; Belgian Collaborative Group on on COVID-19 Hospital Surveillance (2020) Low-dose hydroxychloroquine therapy and mortality in hospitalised patients with COVID-19: a nationwide observational study of 8075 participants. Int. J. Antimicrob. Agents, 56, 106144.

Cavalcanti, A.B., Zampieri, F.G., Rosa, R.G., Azevedo, L.C.P., Veiga, V.C., Avezum, A., Damiani, L.P., Marcadenti, A., Kawano-Dourado, L., Lisboa, T., Junqueira, D.L.M., de Barros, E.S.P.G.M., Tramujas, L., Abreu-Silva, E.O., Laranjeira, L.N., et al. (2020) Hydroxychloroquine with or without azithromycin in mild-to-moderate Covid-19. N. Engl. J. Med., 383, 2041-2052.

Cavanna, L., Citterio, C., Toscani, I., Franco, C., Magnacavallo, A., Caprioli, S., Cattadori, E., Nunzio, C.D., Pane, R., Schiavo, R., Biasini, C. \& Ambroggi, M. (2020) Cancer patients with COVID-19: a retrospective study of 51 patients in the district of Piacenza, Northern Italy. Future Sci. OA, 7, FSO645.

Centers for Disease Control and Prevention (2020) Interim Guidelines for Collecting and Handling of Clinical Specimens for COVID-19 Testing.

https://www.cdc.gov/coronavirus/2019-ncov/lab/guidelines-clinicalspecimens.html [Accessed: March 13, 2021]

Cipriani, A., Zorzi, A., Ceccato, D., Capone, F., Parolin, M., Donato, F., Fioretto, P., Pesavento, R., Previato, L., Maffei, P., Saller, A., Avogaro, A., Sarais, C., Gregori, D., Iliceto, S., et al. (2020) Arrhythmic profile and 24-hour QT interval variability in COVID-19 patients treated with hydroxychloroquine and azithromycin. Int. J. Cardiol., 316, 280-284.

Cunningham, A.C., Goh, H.P. \& Koh, D. (2020) Treatment of COVID-19: old tricks for new challenges. Crit. Care, 24, 91.

Davoodi, L., Abedi, S.M., Salehifar, E., Alizadeh-Navaei, R., Rouhanizadeh, H., Khorasani, G. \& Hosseinimehr, S.J. (2020) Febuxostat therapy in outpatients with suspected COVID-19: a clinical trial. Int. J. Clin. Pract., 74, e13600.

Derwand, R., Scholz, M. \& Zelenko, V. (2020) COVID-19 outpatients: early risk-stratified treatment with zinc plus low-dose hydroxychloroquine and azithromycin: a retrospective case series study. Int. J. Antimicrob. Agents, 56, 106214.

Di Castelnuovo, A., Costanzo, S., Antinori, A., Berselli, N., Blandi, L., Bruno, R., Cauda, R., Guaraldi, G., Menicanti, L., My, I., Parruti, G., Patti, G., Perlini, S., Santilli, F., Signorelli, C., et al. (2020) Use of hydroxychloroquine in hospitalised COVID-19 patients is associated with reduced mortality: findings from the observational multicentre Italian CORIST study. Eur. J. Intern. Med., 82, 38-47.

Esposito, S., Noviello, S. \& Pagliano, P. (2020) Update on treatment of COVID-19: ongoing studies between promising and disappointing results. Infez. Med., 28, 198-211.

Feld, J.J., Kandel, C., Biondi, M.J., Kozak, R.A., Zahoor, M.A., 
Lemieux, C., Borgia, S.M., Boggild, A.K., Powis, J., McCready, J., Tan, D.H.S., Chan, T., Coburn, B., Kumar, D., Humar, A., et al. (2021) Peginterferon lambda for the treatment of outpatients with COVID-19: a phase 2, placebocontrolled randomised trial. Lancet Respir. Med., 9, 498-510.

Feng, Y., Ling, Y., Bai, T., Xie, Y., Huang, J., Li, J., Xiong, W., Yang, D., Chen, R., Lu, F., Lu, Y., Liu, X., Chen, Y., Li, X., Li, Y., et al. (2020) COVID-19 with different severities: a multicenter study of clinical features. Am. J. Respir. Crit. Care Med., 201, 1380-1388.

Horowitz, J. (2020) Italy's healthcare system groans under coronavirus-a warning to the world. New York Times.

https://www.nytimes.com/2020/03/12/world/europe/12italycoronavirus-health-care.html.

[Accessed: March 13, 2021].

Izcovich, A., Ragusa, M.A., Tortosa, F., Lavena Marzio, M.A., Agnoletti, C., Bengolea, A., Ceirano, A., Espinosa, F., Saavedra, E., Sanguine, V., Tassara, A., Cid, C., Catalano, H.N., Agarwal, A., Foroutan, F., et al. (2020) Prognostic factors for severity and mortality in patients infected with COVID-19: a systematic review. PLoS One, 15, e0241955.

Johnston, C., Brown, E.R., Stewart, J., Karita, H.C.S., Kissinger, P.J., Dwyer, J., Hosek, S., Oyedele, T., Paasche-Orlow, M.K., Paolino, K., Heller, K.B., Leingang, H., Haugen, H.S., Dong, T.Q., Bershteyn, A., et al. (2021) Hydroxychloroquine with or without azithromycin for treatment of early SARS-CoV-2 infection among high-risk outpatient adults: a randomized clinical trial. EClinicalMedicine, 33, 100773.

Lai, C.C., Liu, Y.H., Wang, C.Y., Wang, Y.H., Hsueh, S.C., Yen, M.Y., Ko, W.C. \& Hsueh, P.R. (2020) Asymptomatic carrier state, acute respiratory disease, and pneumonia due to severe acute respiratory syndrome coronavirus 2 (SARS-CoV-2): facts and myths. J. Microbiol. Immunol. Infect., 53, 404-412.

Lombardy Section Italian Society Infectious and Tropical Diseases (2020) Vademecum for the treatment of people with COVID19. Edition 2.0, 13 March 2020. Infez. Med., 28, 143-152.

Maniscalco, P., Poggiali, E., Quattrini, F., Ciatti, C., Magnacavallo, A., Caprioli, S., Vadacca, G., Michieletti, E., Cavanna, L. \& Capelli, P. (2020) The deep impact of novel COVID-19 infection in an orthopedics and traumatology department: the experience of the Piacenza Hospital. Acta Biomed., 91, 97-105.

Million, M., Lagier, J.C., Gautret, P., Colson, P., Fournier, P.E., Amrane, S., Hocquart, M., Mailhe, M., Esteves-Vieira, V., Doudier, B., Aubry, C., Correard, F., Giraud-Gatineau, A., Roussel, Y., Berenger, C., et al. (2020) Early treatment of COVID-19 patients with hydroxychloroquine and azithromycin: a retrospective analysis of 1061 cases in Marseille, France. Travel Med. Infect. Dis., 35, 101738.

Mitja, O., Corbacho-Monne, M., Ubals, M., Tebe, C., Penafiel, J., Tobias, A., Ballana, E., Alemany, A., Riera-Marti, N., Perez, C.A., Suner, C., Laporte, P., Admella, P., Mitja, J., Clua, M., et al. (2020) Hydroxychloroquine for early treatment of adults with mild Covid-19: a randomized-controlled trial. Clin. Infect. Dis., doi: 10.1093/cid/ciaa1009. [Epub ahead of print].

Mohana, A., Sulaiman, T., Mahmoud, N., Hassanein, M., Alfaifi, A., Alenazi, E., Radwan, N., AlKhalifah, N., Elkady, E., Almohaizeie, A., AboGazalah, F., AlabdulKareem, K., AlGhofaili, F., Jokdar, H. \& Alrabiah, F. (2021) Hydroxychloroquine safety outcome within approved therapeutic protocol for COVID-19 outpatients in Saudi Arabia. Int. J. Infect. Dis., 102, 110-114.

Nouvenne, A., Zani, M.D., Milanese, G., Parise, A., Baciarello, M., Bignami, E.G., Odone, A., Sverzellati, N., Meschi, T. \& Ticinesi, A. (2020) Lung ultrasound in COVID-19 pneumonia: correlations with chest $\mathrm{CT}$ on hospital admission. Respiration., 99, 617-624.

Ramireddy, A., Chugh, H., Reinier, K., Ebinger, J., Park, E., Thompson, M., Cingolani, E., Cheng, S., Marban, E., Albert, C.M. \& Chugh, S.S. (2020) Experience with hydroxychloro- quine and azithromycin in the Coronavirus disease 2019 pandemic: implications for QT interval monitoring. J. Am. Heart Assoc., 9, e017144.

Risch, H.A. (2020) Early outpatient treatment of symptomatic, high-risk COVID-19 patients that should be ramped up immediately as key to the pandemic crisis. Am. J. Epidemiol., 189, 1218-1226.

Rizk, J.G., Kalantar-Zadeh, K., Mehra, M.R., Lavie, C.J., Rizk, Y. \& Forthal, D.N. (2020) Pharmaco-immunomodulatory therapy in COVID-19. Drugs, 80, 1267-1292.

Saleh, M., Gabriels, J., Chang, D., Soo Kim, B., Mansoor, A., Mahmood, E., Makker, P., Ismail, H., Goldner, B., Willner, J., Beldner, S., Mitra, R., John, R., Chinitz, J., Skipitaris, N., et al. (2020) Effect of chloroquine, hydroxychloroquine, and azithromycin on the corrected QT interval in patients with SARS-CoV-2 infection. Circ. Arrhythm. Electrophysiol., 13, e008662.

Skipper, C.P., Pastick, K.A., Engen, N.W., Bangdiwala, A.S., Abassi, M., Lofgren, S.M., Williams, D.A., Okafor, E.C., Pullen, M.F., Nicol, M.R., Nascene, A.A., Hullsiek, K.H., Cheng, M.P., Luke, D., Lother, S.A., et al. (2020) Hydroxychloroquine in nonhospitalized adults with early COVID-19 : a randomized trial. Ann. Intern. Med., 173, 623-631.

SIMIT (Societ Italiana di Malattie Infettive e Tropicali) (2020) Vademecum per la cura delle persone con infezione da SARSCoV-2.

https://www.simit.org/images/Vademecum\%203.0\%20del\%20 03.11.2020.pdf [Accessed: June 03, 2021].

Sogut, O., Can, M.M., Guven, R., Kaplan, O., Ergenc, H., Umit, T.B., Demir, O., Kaya, M., Akdemir, T. \& Cakmak, S. (2021) Safety and efficacy of hydroxychloroquine in 152 outpatients with confirmed COVID-19: a pilot observational study. Am. J. Emerg. Med., 40, 41-46.

Stroppa, E.M., Toscani, I., Citterio, C., Anselmi, E., Zaffignani, E., Codeluppi, M. \& Cavanna, L. (2020) Coronavirus disease2019 in cancer patients. A report of the first 25 cancer patients in a western country (Italy). Future Oncol., 16, 1425-1432.

Sulaiman, T., Mohana, A., Alawdah, L., Mahmoud, N., Hassanein, M., Wani, T., Alfaifi, A., Alenazi, E., Radwan, N., AlKhalifah, N., Elkady, E., Alanazi, M., Alqahtani, M., Abdullah, K., Yousif, Y., et al. (2020) The effect of early hydroxychloroquine-based therapy in COVID-19 patients in ambulatory care settings: a nationwide prospective cohort study. MedRxiv, doi: 10.1101/2020.09.09.20184.

Tardif, J.C., Bouabdallaoui, N., L’Allier, P.L., Gaudet, D., Shah, B., Pillinger, M.H., Lopez-Sendon, J., da Luz, P., Verret, L., Audet, S., Dupuis, J., Denault, A., Pelletier, M., Tessier, P.A., Samson, S., et al. (2021) Colchicine for community-treated patients with COVID-19 (COLCORONA): a phase 3, randomised, double-blinded, adaptive, placebo-controlled, multicentre trial. Lancet Respir. Med., 9, 924-932.

U.S. Department of Health and Human Services. National Institutes of Health National Cancer Institute (2009) Common Terminology Criteria for Adverse Events (CTCAE) Version 4.0. https://evs.nci.nih.gov/ftp1/CTCAE/CTCAE_4.03/Archive/ CTCAE_4.0_2009-05-29_QuickReference_8.5x11.pdf [Accessed: April 18, 2021].

Wang, L., Wang, Y., Ye, D. \& Liu, Q. (2020) Review of the 2019 novel coronavirus (SARS-CoV-2) based on current evidence. Int. J. Antimicrob. Agents, 55, 105948.

World Health Organization (2020) WHO Director-General's opening remarks at the media briefing on COVID-19 - 11 March 2020

https://www.who.int/director-general/speeches/detail/whodirector-general-s-opening-remarks-at-the-media-briefing-oncovid-19---11-march-2020

[Accessed: June 03, 2021]. 
Worldometer (2020) COVID-19 coronavirus pandemic. https://www.worldometers.info/coronavirus/ [Accessed: April 16, 2021].

Wynants, L., Van Calster, B., Collins, G.S., Riley, R.D., Heinze, G., Schuit, E., Bonten, M.M.J., Dahly, D.L., Damen, J.A.A., Debray, T.P.A., de Jong, V.M.T., De Vos, M., Dhiman, P., Haller, M.C., Harhay, M.O., et al. (2020) Prediction models for diagnosis and prognosis of covid-19: systematic review and critical appraisal. $B M J, \mathbf{3 6 9}, \mathrm{m} 1328$.

Yang, W., Sirajuddin, A., Zhang, X., Liu, G., Teng, Z., Zhao, S. \& $\mathrm{Lu}, \mathrm{M}$. (2020a) The role of imaging in 2019 novel coronavirus pneumonia (COVID-19). Eur. Radiol., 30, 4874-4882.
Yang, Y., Xiao, Z., Ye, K., He, X., Sun, B., Qin, Z., Yu, J., Yao, J., Wu, Q., Bao, Z. \& Zhao, W. (2020b) SARS-CoV-2: characteristics and current advances in research. Virol. J., 17, 117.

Zhao, N., Zhou, Z.L., Wu, L., Zhang, X.D., Han, S.B., Bao, H.J., Shu, Y. \& Shu, X.G. (2020) An update on the status of COVID-19: a comprehensive review. Eur. Rev. Med. Pharmacol. Sci., 24, 4597-4606.

Zheng, Z., Peng, F., Xu, B., Zhao, J., Liu, H., Peng, J., Li, Q., Jiang, C., Zhou, Y., Liu, S., Ye, C., Zhang, P., Xing, Y., Guo, H. \& Tang, W. (2020) Risk factors of critical \& mortal COVID-19 cases: a systematic literature review and metaanalysis. J. Infect., 81, e16-e25. 